\title{
Evaluation of the Potential of Cadmium and Dyes Removal by Chitosan Obtained from Zygomycetes
}

Freitas JHES ${ }^{1,6}$, Mahnke LC ${ }^{2,6}$, Estevam-Alves MHM ${ }^{3,6}$, Santana KV ${ }^{4,6}$, Campos-Takaki GM ${ }^{5,6}$ and Nascimento $\mathrm{AE}^{5,6^{*}}$

${ }^{1}$ Biochemistry and Physiology, UFPE, Recife/Pernambuco, Brazil

${ }^{2}$ Biological Sciences, UFPE, Recife/Pernambuco, Brazil

${ }^{3}$ Biology Applied to Health, UFPE, Recife/Pernambuco, Brazil

${ }^{4}$ Development of Processes in Environmental Sciences, Unicap, Recife/Pernambuco, Brazil

${ }^{5}$ Catholic University of Pernambuco, Recife/Pernambuco, Brazil

${ }^{6}$ Nucleus of Research in Environmental Sciences and Biotechnology, Unicap, Recife/Pernambuco, Brazil

"Corresponding author: Aline Elesbão do Nascimento, Nucleus of Research in Environmental Sciences and Biotechnology, Unicap, Recife/Pernambuco - Brazil, Tel: +55 812119 4050; E-mail: elesbao@unicap.br

Received date: February 23, 2015; Accepted date: June 29, 2015; Published date: July 06, 2015

Copyright: (c) 2015 Freitas JHES, et al. This is an open-access article distributed under the terms of the Creative Commons Attribution License, which permits unrestricted use, distribution, and reproduction in any medium, provided the original author and source are credited.

\begin{abstract}
Background: Treatment process for heavy metal and dye removal is a worrying factor in environmental health because it can contribute to the formation of new contaminants.

Objectives: To obtain and use chitosan from Zygomycetes for removal process of heavy metal (cadmium) and azodyes (Reactive Black and Remazol Red).

Methods: Chitosan was obtained by Rhizopus arrhizus UCP 402 and Mucor javanicus UCP 69 following the described method of Synowiecki and Al-Khateeb (1997) and submitted to removal tests for $18 \mathrm{~h}$, with different concentrations of Cadmium (0.5-4 mM), Reactive Black (B) and Remazol Red (1-1000 mg/L) in orbital shaker under $150 \mathrm{rpm}$ at $28^{\circ} \mathrm{C}$. Then, the samples were submitted to spectrophotometry and chitosan exposed to the contaminants were submitted to electronic microscopy analysis.
\end{abstract}

Results: The efficiency of cadmium removal by Rhizopus arrhizus chitosan showed data of $92 \%(0.5 \mathrm{mM})$, $92.8 \%(1 \mathrm{mM}), 75.9 \%(2 \mathrm{mM}), 54 \%(3 \mathrm{mM})$ and $54.5 \%(4 \mathrm{mM})$ at $\mathrm{pH} 6.0$. The efficiency of dyes removal by Mucor javanicus chitosan was about 100\% (1 mg/L), 100\% (10 mg/L), 100\% (50 mg/L), 98\% (100 mg/L), 55\% (1000 mg/L) for Reactive Black (B) and 100\% (1 mg/L), 100\% (10 mg/L), 100\% (50 mg/L), 98\% (100 mg/L), 59\% (1000 mg/L) for Remazol Red.

Conclusion: Chitosan obtained by the strains was capable of removing cadmium and the reactive dyes: Reactive Black (B) and Remazol Red in all conditions tested.

Keywords: Zygomycetes; Rhizopus arrhizus; Mucor javanicus; Dye; Heavy metal; Removal; Chitosan

\section{Introduction}

The heavy metal contamination is now one of the most worrying factors for environmental health, as they are easily transported in solution, and can reach high concentrations in enclosed areas on their own, or for biological amplification [1].

Cadmium is widely used in the manufacture of batteries, electroplating, pigments, metal alloys of low melting point, electrolytic coating of metals, enamels and textile dyes in control rods in nuclear fission, among others. The metal is discharged to the environment can contaminate air, water and soil. The metal ions are responsible for protein denaturation and reduction of enzyme activity. Several examples of this effect have been described for enzymes of the Krebs cycle [1-3].
The textile industry has one of the largest generations of polluting processes, contributing quantitatively and qualitatively with pollution load rejected in the environment, covering five different fields: liquid effluents, emissions and particles, solid waste, odors and noise. When this effluent is disposed, it can cause impacts on the receiving body originating from its pollution load, and contamination because the textile effluents have high values for color levels, chemical and biochemical oxygen demand, suspended solids and low dissolved oxygen concentrations [4]. These dyes (natural or xenobiotic) in a particular environment typically remain unchanged or have a very slow degradation kinetics for the conventional biological processes, and generate the final effluent (after treatment), which still very intense staining. The dye molecule has a structure responsible for the absorption of visible radiation exposure and color, the family of azo dyes is the most used, corresponding to roughly $70 \%$ of all textile dyes produced and can produce byproduct substances inducing carcinogenic and mutagenic effects [5-7]. 
Citation: Freitas JHES, Mahnke LC, Estevam-Alves MHM, Santana KV, Campos-Takaki GM, et al. (2015) Evaluation of the Potential of Cadmium and Dyes Removal by Chitosan Obtained from Zygomycetes. J Mol Genet Med S4: 003. doi:10.4172/1747-0862.S4-003

Page 2 of 4

Treatment processes for dye removal are based on the operation of physical-chemical systems as precipitation-coagulation systems, followed by separation by sedimentation through biological treatment via activated sludge system, with a high efficiency particulate removal. However, there are many difficulties in the removal of color and dissolved organic compounds, in addition to the great disadvantage of being very susceptible to the effluent composition (shock loads), and producing a large volume of sludge $[5,7,8]$. Currently there are physical and chemical processes of precipitation, flocculation, electrolysis, crystallization or adsorption for the decontamination of heavy metals in environments, however, these processes can be burdensome and/or contribute to formation of new environmental contaminants, so it becomes necessary to develop more cost-effective technologies and practices for the removal of these elements, which are responsible for a high level of toxicity to living systems. Thus different techniques and processes have been used aiming at the removal of xenobiotic [1,3,5-8].

The Zygomycetes class is composed of fungi naturally saprophytic and cosmopolitan. Additionally, due to its participation in the biodegradation processes (attacking materials from various sources such as leather, plastic, wood and food), biodegradation (mainly waste recycling and training of fertilizer), bioremediation and industry (production of enzymes, fatty acids, antibiotics, preservatives and lactic acids), have great economic importance $[9,10]$.

Chitosan is derived from chitin. It is nontoxic, biodegradable, and renewable natural sources obtained whose properties have been exploited in industrial applications and technology there is nearly seventy extracted from the shell of arthropods and the cell walls of micro-organisms. These two native or chemically modified polymers occupy a wide area of application in various industries, in medical technology and also due to the significant physical and chemical characteristics suitable as biodegradability, biocompatibility, antimicrobial action, among other applications [11-14].

For this study, we evaluated the Cadmium, Remazol Red and Reactive Black (B) removal efficiency by the chitosan obtained from Rhizopus arrhizus UCP 402 and Mucor javanicus UCP 69.

\section{Materials and Methods}

\section{Microorganism and culture conditions}

Rhizopus arrhizus UCP 402 and Mucor javanicus UCP 69 were obtained from the Culture Collection of the Nucleus of Research in Environmental Science and Biotechnology - Catholic University of Pernambuco - Brazil, included in the Rede Nordestina de Microorganismos do Norte e Nordeste (RENEBRA) and registered in the World Federation Culture Collection (WFCC). The strains were maintained in Potato Dextrose Agar (PDA) at $5^{\circ} \mathrm{C}$. The fungus was cultivated in Synthetic Medium of Mucoralean in order to produce spores and incubated at $28{ }^{\circ} \mathrm{C}$ for 6 days, for the production of preinoculum.

\section{Extraction of Chitosan of Rhizopus arrhizus and Mucor javanicus}

The biomasses were produced through Synthetic Medium of Mucoralean, using Erlenmeyer flasks with $1000 \mathrm{~mL}$ of capacity, incubated at $150 \mathrm{rpm}$ at $28^{\circ} \mathrm{C}$ for 15 days. The biomasses produced in SMM medium were collected by filtration and washed in distilled water. The biomasses obtained were used for extraction of chitosan.
The process involves deproteinization by $2 \%$ sodium hydroxide $(\mathrm{w} / \mathrm{v})$, followed by centrifugation, acid hydrolysis of $10 \%$ acetic acid (v/v) to obtain chitin and successive washings with acetone and ethanol for precipitation of polysaccharides. Chitosan was obtained by deacetylation of chitin [15].

\section{Chitosan characterization}

The degree of deacetylation (DD\%) for microbial chitosan was determined using the infrared spectroscopy in the absorbance ratio A1655/A3450 and calculated according to the equation:

$$
\mathrm{A}(\%)=(\mathrm{A} 1655 / \mathrm{A} 3450) \times 100 / 1.33
$$

Two milligrams sample of fungal chitin and chitosan, which had been dried overnight at $60^{\circ} \mathrm{C}$ under reduced pressure were thoroughly blended with $100 \mathrm{mg}$ of $\mathrm{KBr}$, to produce $0.5 \mathrm{~mm}$ thick disks. The disks were dried for 24 hours at $110^{\circ} \mathrm{C}$ under reduced pressure. Infrared spectrometer was recorded with a Bruker 66 Spectrometer, using a 100 $\mathrm{mg} \mathrm{KBr}$ disks for reference. The intensity of maximum absorption bands were determined by the baseline method.

\section{Cadmium and dyes removal tests}

Chitosan was tested under the following conditions: a solution of chitosan $1 \%(\mathrm{w} / \mathrm{v})$ was added in $125 \mathrm{ml}$ of cadmium with different concentrations $(0.5 \mathrm{mM}-4 \mathrm{mM})$ and $\mathrm{pH}(4.0-6.0)$ or reactive dyes solutions (Reactive Black (B) and Remazol Red) with different concentrations (1 mg/L-1000 mg/L) and $\mathrm{pH} 4.0$. The samples were placed under orbital shaker at $150 \mathrm{rpm}$ at $28^{\circ} \mathrm{C}$ for 18 hours.

\section{Determination of Cadmium and dyes removal efficiency from biomass, chitin and chitosan}

Samples under the conditions mentioned above were subjected to atomic absorption spectrophotometry (cadmium) and spectrophotometry UV-visible (dyes) to determine the residual concentration of each sample. All experiments were performed in triplicate.

Efficiency of removal:

$$
\begin{aligned}
& \mathrm{q}=\left(\mathrm{C}_{0}-\mathrm{C}_{\mathrm{f}}\right) / \mathrm{m} \\
& \mathrm{R} \%=\left[\left(\mathrm{C}_{0}-\mathrm{C}_{\mathrm{f}}\right) 100\right] / \mathrm{C} 0 \\
& \mathrm{C}_{0}-\text { Initial concentration } \\
& \mathrm{C}_{\mathrm{f}}-\text { Final concentration }
\end{aligned}
$$

\section{Ultrastructural analysis - scanning electronic microscopy}

Samples collected were washed twice in PBS, pH 7.2, for 10 minutes. Then they were fixed with $2.5 \%$ glutaraldehyde in $0.1 \mathrm{M}$ phosphate buffer, $\mathrm{pH} 7.4$, for 1 hour at room temperature. After the stage-setting, all samples were washed again twice with phosphate buffer, for 10 minutes. This procedure was followed by the post-fixing with osmium tetroxide $1 \%$ in phosphate buffer, for 1 hour at room temperature, in absence of light. Then the samples were once again washed with $0.1 \mathrm{M}$ phosphate buffer, and submitted to the process of dehydration. The dehydration of the samples was done with ethanol, in concentrations of $50 \%, 70 \%, 90 \%$ ( 5 minutes for each exchange) until the proportion of $100 \%$ (three times, 10 minutes each exchange). After this step, the samples were submitted to the critical point, followed by the assembly in support of aluminum and subsequent gold metallization. Once 
Citation: Freitas JHES, Mahnke LC, Estevam-Alves MHM, Santana KV, Campos-Takaki GM, et al. (2015) Evaluation of the Potential of Cadmium and Dyes Removal by Chitosan Obtained from Zygomycetes. J Mol Genet Med S4: 003. doi:10.4172/1747-0862.S4-003

Page 3 of 4

prepared, samples were examined and photographed in the Scanning Electronic Microscope, JEOL LV 5600, operating at $20 \mathrm{KV}$.

\section{Results}

The use of these isolated was based in the literature that reveals the potential of Rhizopus arrhizus and Mucor javanicus in processes of biosorption in aqueous solution as well as the extraction of chitin and chitosan from their biomass and its possible application in bioremediation processes.

Deacetylation degree (\%DD) is an important parameter associated with the physical-chemical properties of chitosan, because it's linked directly to the chitosan cationic properties. In the present study chitosan from Mucor javanicus UCP 69 and Rhizopus arrhizus UCP 402 presented $76.2 \% \mathrm{DD}$ and $84 \% \mathrm{DD}$, respectively.

The results of cadmium and reactive dyes removal efficiency are showed in Figure $1(\mathrm{~A}, \mathrm{~B})$.

A

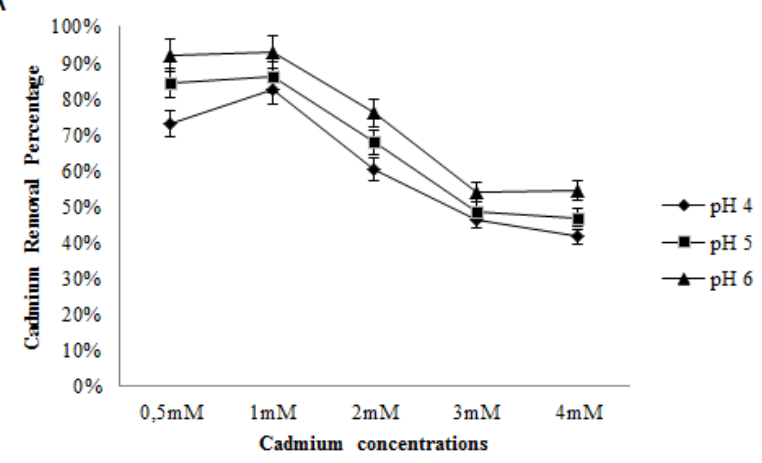

B

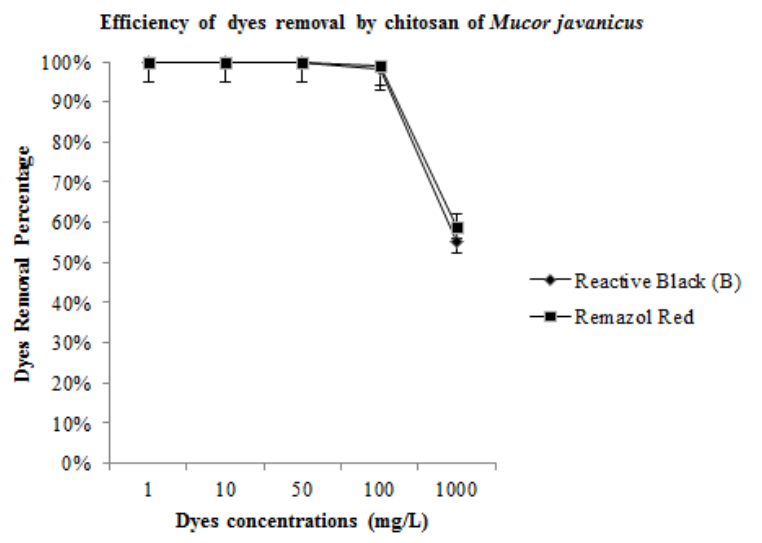

Figure 1: Graphs of removal efficiency. (A) - Efficiency of cadmium removal by Rhizopus arrhizus chitosan. (B) - Efficiency of reactive dyes removal by Mucor javanicus chitosan.

The efficiency of cadmium removal by Rhizopus arrhizus chitosan showed data of $73 \%, 84 \%$ and $92 \%(0.5 \mathrm{mM}) ; 82 \%, 86 \%$ and $92.8 \%(1$ $\mathrm{mM}) ; 60 \%, 68 \%$ and $75.9 \%(2 \mathrm{mM}) ; 46 \%, 49 \%$ and $54 \%(3 \mathrm{mM})$ and $41 \%, 47 \%$ and $54.5 \%(4 \mathrm{mM})$ at $\mathrm{pH} 4.0,5.0$ and 6.0 , respectively. Additionally, Rhizopus arrhizus chitosan was capable to remove 438.45 $\mathrm{mg} / \mathrm{L}$ of cadmium in a solution with $4 \mathrm{mM}(805.32 \mathrm{mg} / \mathrm{L})$.
Furthermore, the effect of $\mathrm{pH}$ removal system was also evaluated, where $\mathrm{pH}$ values below 4.0 induced metal precipitation in the solution. The data showed that at increasing $\mathrm{pH}$ values the removal system was more effective. Thus, a higher removal was obtained at $\mathrm{pH}$ 6.0.

The literature reveals removal of metals such as cadmium, zinc, copper, cobalt, uranium, nickel chromium by biomass, non-viable or dead filamentous fungi, with special emphasis on species of Aspergillus and Rhizopus. The papers point out that the concentrations of metals vary and responses depend on their concentration and the type of biomass. Additionally, it is possible to increase the removal of heavy metals as a result of physical pre-treatment and/or chemicals. Thus the living cells can be inactivated with chemical agents such as acids, alkali, detergents, organic solvents, aldehydes (formaldehyde, glutaraldehyde) which increase the access of metal ion binding sites. Moreover, chitin and chitosan are also reported as materials with high adsorptive power to xenobiotics [1,2].

The efficiency of dyes removal by Mucor javanicus chitosan was about $100 \%$ and $100 \%(1 \mathrm{mg} / \mathrm{L}) ; 100 \%$ and $100 \%(10 \mathrm{mg} / \mathrm{L}) ; 100 \%$ and $100 \%(50 \mathrm{mg} / \mathrm{L}) ; 97.8 \%$ and $98 \%(100 \mathrm{mg} / \mathrm{L})$ and $55 \%$ and $58 \%(1000$ $\mathrm{mg} / \mathrm{L}$ ) for Reactive Black (B) and Remazol Red, respectively.

A study of the reactive dye adsorption in solutions with use of chitosan showed excellent adsorptive ability, between 1000-1100 mg per gram of biomass. The data presented show that the isolate was evaluated capable of removing reactive dyes, Reactive Black (B) and Remazol Red in all conditions tested [5].

In this study, the electrondensity of chitosan obtained by Rhizopus arrhizus and Mucor javanicus was observed in Eletronic Microscopy as followed in Figure 2 (A-D).
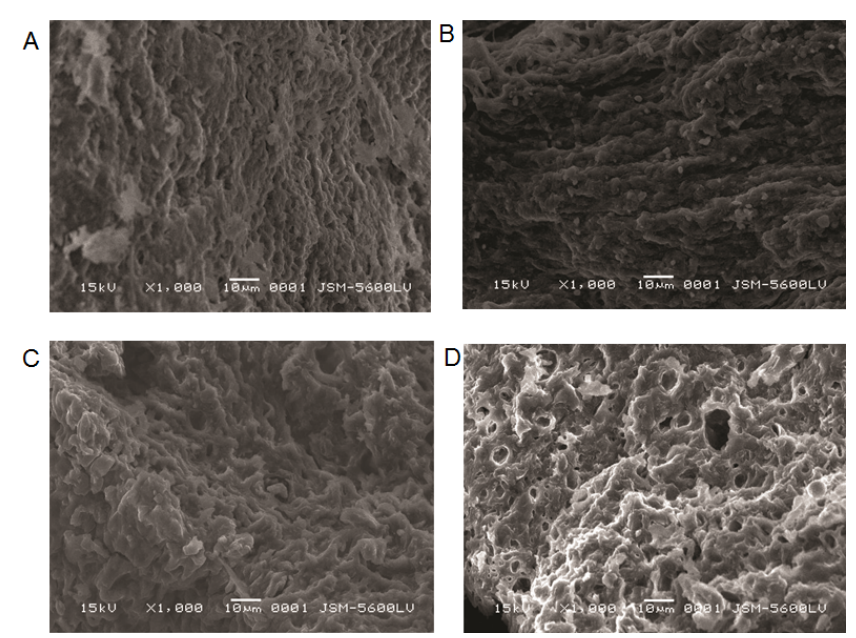

Figure 2: Micrographs of chitosan. A - Control; B - Rhizopus arrhizus chitosan submitted to $4 \mathrm{mM}$ of cadmium; C - Mucor javanicus chitosan submitted to1000 $\mathrm{mg} / \mathrm{L}$ of Reactive Black (B); D - Mucor javanicus chitosan submitted to $1000 \mathrm{mg} / \mathrm{L}$ of Remazol Red.

Ultrastructural changes like heterogeneity and variations in electrondensity are also reported as a result of exposure to metal ions or xenobiotic associated to heavy metals as textile dyes. By the absence of cellular and extracellular materials, chitosan has a great affinity to ligands and, hence, a large adsorption capacity. 
Citation: Freitas JHES, Mahnke LC, Estevam-Alves MHM, Santana KV, Campos-Takaki GM, et al. (2015) Evaluation of the Potential of Cadmium and Dyes Removal by Chitosan Obtained from Zygomycetes. J Mol Genet Med S4: 003. doi:10.4172/1747-0862.S4-003

Page 4 of 4

\section{Discussion}

Among the numerous techniques for removal of heavy metals and dyes, adsorption is the process of choice and offers the best results, as it can be used to remove different types of recalcitrant agents. In order to improve adsorption processes, the use of fungal biomass has been receiving great attention because of its variety and versatility. The microorganisms in general can accumulate or transform xenobiotics, as a result of specific enzymatic reactions or mechanisms resulting in the characteristics and properties of the cell wall and the plasma membrane [16].

In recent years several approaches have been used for the development of cheap and effective adsorbents. Thus, in recent years, several researchers have demonstrated the ability of various microorganisms to transform azo compounds in non-colored products, in addition to the complete mineralization of the molecules under certain environmental conditions $[17,18]$.

Bioremediation is the use of biomass, grown or obtained as coproduct of fermentation, subjected to drying and grounding, as well as their derivatives, generating lower costs, reduced waste and tailings and high efficiency in the removal of heavy metals and dyes in wastewater very diluted. Many biological systems have been evaluated in the removal of heavy metals from aqueous solutions as a means for environmental control. The literature shows that the application of dead biomass or subjected to physical and chemical treatments has advantages in relation to living biomass with regard to the elimination of xenobiotic toxicity [19-21].

Chitin and chitosan are polysaccharides with a chemical structure similar to cellulose, and have been studied as adsorbents. Chitin is the most abundant natural polymer and is found in the carapace of crustaceans and cellular walls of fungi, for example of the class Zygomycetes. Chitosan, on the other hand, is the deacetilated form of chitin. Both chitin and chitosan are used as attractive sources of adsorbents for heavy metals. In recent years both materials are also used in assays for removal of xenobiotics in general, and chitosan has been a biosorbent with a great efficiency, because the presence of ionic groups imparts unique properties to this biopolymer [12-15].

\section{Conclusions}

The data presented show that chitosan obtained by the strains was capable of removing Cadmium and the reactive dyes: Reactive Black (B) and Remazol Red in all conditions tested. Chitosan also showed high potential onto discoloration of dyes. Thus, studies using synthetic wastewater to determine essential parameters of the removal process and increase its efficiency can be proposed for obtaining biosorbents for dyes and heavy metals.

\section{Acknowledgements}

We're thankful to CNPq, CAPES, FACEPE and UNICAP for the financial support.

\section{References}

1. Gadd GM (2010) Metals, minerals and microbes: geomicrobiology and bioremediation. Microbiology 156: 609-643.

This article was originally published in a special issue, entitled: "Medicinal

Applications of Bioactive Compounds", Edited by Bugra Ocak
2. Rhee YJ, Hillier S, Gadd GM (2012) Lead transformation to pyromorphite by fungi. Curr Biol 22: 237-241.

3. Kaushik P, Malik A (2011) Process optimization for efficient dye removal by Aspergillus lentulus FJ172995. J Hazard Mater 185: 837-843.

4. Chakraborty S, Basak B, Dutta S, Bhunia B, Dey A (2013) Decolorization and biodegradation of congo red dye by a novel white rot fungus Alternaria alternata CMERI F6. Bioresour Technol 147: 662-666.

5. Gul UD, Donmez G (2013) Application of mixed fungal biomass for effective reactive dye removal from textile effluents. Desal Wat Treat 51: 16-18

6. Gul UD, Donmez G (2014) Influence of Surfactants on Dye Removal and Growth of Aspergillus vesicolor-an Effective Way to Decolorize Textile Dye. Clean S A W 42: 917-922

7. Lopes MMG, Sales PTF, Campos LC, Schimidt F, Santiago MF (2014) Study of decolorization of FD\&C blue \#2 indigotine by fungus Trametes versicolor combined with slow sand filtration. Eng Sanit Ambient 19.

8. Fu Y, Viraraghavan T (2001) Fungal decolorization of dye wastewaters: a review. Bioresour Technol 79: 251-262.

9. Alexopoulos CJ, Mims CW, Blackwell M (2001) Introductory Mycology (4thed), John Wiley \& Sons, Pub. Co. Inc., London, 233.

10. Kiran I, Akar T, Tunali S (2005) Biosorption of $\mathrm{Pb}(\mathrm{II})$ and $\mathrm{Cu}(\mathrm{II})$ from aqueous solutions by pretreated biomass of Neurospora crassa. Proc Biochem 40: 3550-3558.

11. Vakili M, Rafatullah M, Salamatinia B, Abdullah AZ, Ibrahim MH, et al. (2014) Application of chitosan and its derivatives as adsorbents for dye removal from water and wastewater: a review. Carbohydr Polym 113: 115-130.

12. Zinadini S, Zinatizadeh AA, Rahimi M, Vatanpour V, Zangeneh H, et al. (2014) Novel high fluz antifouling nanofiltration membranes for dye removal containing carboxymethyl chitosan coated Fe3O4 nanoparticles. Desal 349: 145-154

13. Oliveira CS, Airoldi C (2014) Pyridine derivative covalently bonded on chitosan pendant chains for textile dye removal. Carbohydr Polym 102: 38-46.

14. Crini G, Morin-Crini N, Fatin-Rouge N, DÃ@on S, Fievet P (2014) Metal removal from aqueous media by polymer-assisted ultrafiltration with chitosan. Arab J Chem.

15. Synowiecki J, Al-Khateeb NAAQ (1997) Mycelia of Mucor rouxii as a source of chitin and chitosan. Food Chem 60: 605-610.

16. Fomina M, Gadd GM (2014) Biosorption: current perspectives on concept, definition and application. Bioresour Technol 160: 3-14.

17. Gadd GM (2013) Microbial Roles in Mineral Transformations and Metal Cycling in the Earth's Critical Zone. Mol Env Soil Sci 115-165

18. Hasunuma T, Okazaki F, Okai N, Hara KY, Ishii J, et al. (2013) A review of enzymes and microbes for lignocellulosic biorefinery and the possibility of their application to consolidated bioprocessing technology. Bioresour Technol 135: 513-522.

19. Hadibarata T, Yusoff ARM, Kristanti RA (2012) Acceleration of Anthraquinone-Type Dye Removal by White-Rot Fungus Under Optimized Environmental Conditions. Wat Air Soil Pol 223: 4669-4677.

20. Haldorai Y, Shim J (2014) An efficient removal of methyl orange dye from aqueous solution by adsorption onto chitosan/MgO composite: A novel reusable adsorbent. App Sur Sci 292: 447-453.

21. Jadhav U, Hocheng H (2014) Use of Aspergillus niger 34770 culture supernatant for tin metal removal. Corr Sci 82: 248-254. 